\title{
Enterobius Vermicularis Infestation of the Uterine Cavity: A Rare Cause of Dysfunctional Uterine Bleeding
}

\author{
D Hasan Ali İnal, ${ }^{1}$ (D) Zeynep Öztürk İnal, ${ }^{1}$ (D) Tuğba Günler² \\ 'Departmant of Gynecology, Konya Training and Research Hospital, Konya, Turkey \\ ${ }^{2}$ Departmant of Pathology, Konya Training and Research Hospital, Konya, Turkey
}

\section{ABSTRACT}

Extraintestinal infestations of Enterobius are extremely rare, and the worm larvae may migrate primarily to invade the female genital tract. A 47-year-old woman having irregular menstruation for six months was admitted and had endometrial biopsy. The patient, whose pathology report had enterobiasis in the endometrium, was cured by treatment with $500 \mathrm{mg}$ mebendazole. Endometrial sampling should be considered by the clinician before unnecessary and aggressive surgery in patients presenting with a similar complaint.

Keywords: Dysfunctional uterine bleeding, endometrium, Enterobius Vermicularis

Please cite this article as: İnal HA, Öztürk İnal Z, Günler T. Enterobius Vermicularis Infestation of the Uterine Cavity: A Rare Cause of Dysfunctional Uterine Bleeding. Anatol J Family Med 2020;3(3):264-266.

Address for correspondence: Dr. Hasan Ali İnal. Departmant of Gynecology, Konya Training and Research Hospital, Konya, Turkey

Phone: +90 5334788299

E-mail:

dr.hasanaliinal@yahoo.com

Received Date: 09.04.2020

Accepted Date: 25.05 .2020

Published online: 04.11.2020

(C) Copyright 2020 by Anatolian Journal of Family Medicine -

Available online at

Www.anatoljfm.org

OPEN ACCESS

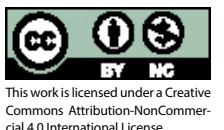

\section{INTRODUCTION}

Enterobius vermicularis (also known as oxyuris, pinworm, and threadworm) is an intestinal nematode that can lead to an infestation in countries with temperate climates, has low pathogenicity and is often asymptomatic except for perianal itching. ${ }^{[1]}$ The main cause of contamination is the oral ingestion of worm eggs by uninfected people. Aworm becomes an adult in the intestine and, soon after copulation the male worm dies, the gravid female worm migrates to the rectum and perianal region and lays eggs at night. ${ }^{[2,3]}$ Pinworms extraintestinal are extremely rare, and the worm larvae can migrate primarily to invade the female genital tract (vagina, endometrium, myometrium, tuba uterine, ovary, and pelvic peritoneum) and even the male urinary tract (renal pelvis, prostate). ${ }^{[4]}$ Pinworm ova and larvae cervicovaginal smear may be seen and may cause salpingitis, endometritis, pelvic abscess, and generalized peritonitis. ${ }^{[1,4]}$

A limited number of enterobiasis infestations in the female reproductive system have been described in the literature. We present a case of Enterobius vermicularis infestation as a result of endometrial sampling in a 47-year-old women with dysfunctional uterine bleeding.

\section{CASE REPORT}

There was no significant pathology in the medical history of a 47-year-old woman who had irregular menstruation for six months and had no improvement in her menstruation despite cyclic progesterone treatment in the last three months. Physical examination of the patient was also normal, and no abnormal condition was observed during vaginal examination. In 
the transvaginal ultrasonography (USG) evaluation, the uterus dimensions were $60.0 \times 40.0 \mathrm{~mm}$ within normal limits, and their regular hyperechogenic area of $10.0 \times 10.0$ $\mathrm{mm}$ in the endometrial cavity, myometrium and bilateral adnexes were observed to be normal. The patient's blood cell count, biochemical tests, and tumor markers were within normal limits (Table 1). Endometrial biopsy was decided due to their regular hyperechogenic appearance in the endometrial cavity. The material obtained by an endometrial biopsy was sent to the pathology department for histopathological evaluation. In the final pathological examination, a chronic inflammatory endometrium containing necrotic areas of the Enterobius vermicularis ova in the hematoxylin-eosin stained preparation, mostly surrounded by lymphocytes and eosinophils (Figure 1). Thereupon, 500 $\mathrm{mg}$ of mebendazole medical treatment was given orally to the patient and first-degree relatives once a day, the treatment was repeated two weeks later, and she was called for a gynecological examination three months later.

\section{DISCUSSION}

Enterobius vermicularis, also known as Oxyuris, pinworm, or threadworm, is the most common helminthic infestation and is transmitted by the ingestion of 20 microns wide and 40 microns long ova by a contaminated hand or food. After fertilization in the cecum or terminal ileum, mature female worms migrate to the rectum or perianal region and lay their eggs after contact with air. As a result of itching,

\section{Table 1. The laboratory parameters of the case}

\section{Parameters}

Hemoglobin $(\mathrm{g} / \mathrm{dL})$

WBC $\left(10^{3} / \mathrm{mL}\right)$

Platelet $\left(10^{3} / \mathrm{mm}^{3}\right)$

AST (U/L)

ALT (U/L)

GGT (U/L)

BUN (mg/dl)

Creatinine $(\mathrm{mg} / \mathrm{dl})$

Fasting blood glucose (mg/dL)

CA $125(\mathrm{U} / \mathrm{mL})$

CA $15-3(\mathrm{U} / \mathrm{mL})$

CA-19.9 (U/mL)

CEA (ng/ml)

AFP $(\mathrm{U} / \mathrm{mL})$

\section{Results (Reference values)}

$12.24(11.9-14.6)$

8.34 (4.49-12.68)

$275(150-450)$

$22.8(0.0-35.0)$

$24.6(0.0-35.0)$

$15.4(0.0-38.0)$

$16.5(17.0-43.0)$

$0.48(0.66-1.09)$

$84.7(74.0-106.0)$

$9.2(1.9-18.0)$

$16.2(0.0-38.0)$

$5.4(0.0-33.0)$

$1.8(0.0-5.0)$

$1.1(0-8.2 .0)$
AFP: Alpha-Fetoprotein; ALT: Alanine Aminotransferase; AST: Aspartate Aminotransferase; BUN: Blood Urea Nitrogen; CA: Cancer Antigen; CEA: Carcinoembryonic Antigen; GGT: Gama Glutamyl Transferase; WBC: White Blood Cell.

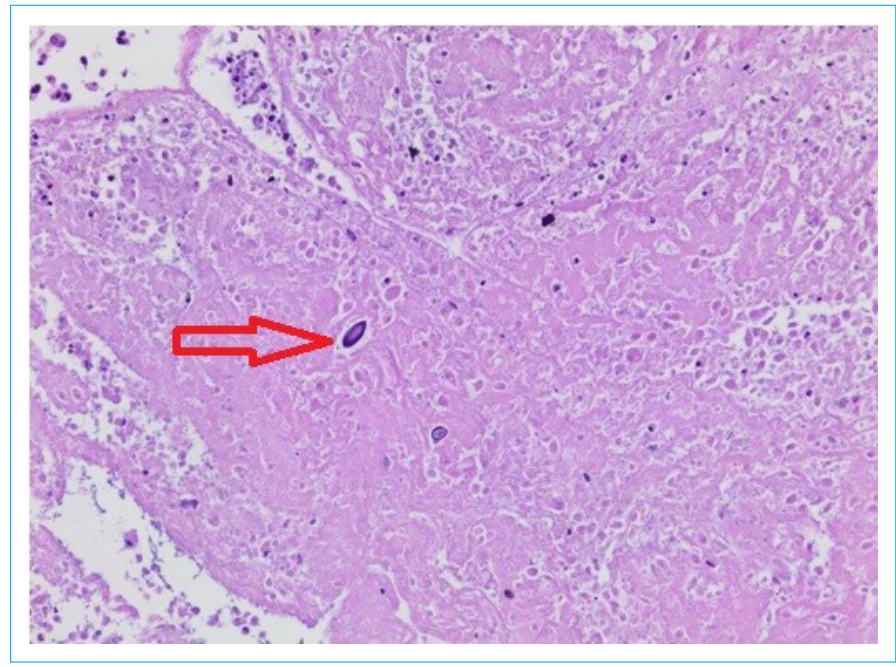

Figure 1. The Enterobius vermicularis egg is between the endometrial gland and fibrinoid material (H\&E, x200).

the original host may infect other areas (autoinfection) or contaminate other people. An otherway of transmission is the ingestion of ova by inhalation or digestion through food. ${ }^{[1,5]}$

Extraintestinal infestation is extremely rare and may cause appendicitis, recurrent urinary infection, peritonitis, and abdominal pain.$^{[6]}$ Adult pinworms may pass from the perianal region to the vagina, endometrium, fallopian tubes, and peritoneal cavity, and cause vulva-vaginitis, salpingitis, pelvic pain, pelvic mass, tuba-ovarian abscess, dysfunctional uterine bleeding, infertility, and post-menopausal bleeding. ${ }^{[3]}$ In addition, it can even pass in to the urethra or bladder and cause urinary leakage. In some cases, pinworms can develop a granulomatous formation and a transvaginal USG image may be confused with the fibroma, leiomyoma, endometrioma, and endometrial cancer. ${ }^{[2,6,7]}$

Enterobius infestation has been reported in the genital tract of postmenopausal women in the literature. It has been claimed that the pinworm migrates from the vagina to the endometrial cavity before menopause and remains latent in the cavity for years after the cervical canalis closed in the post-menopausal period. ${ }^{[2]}$ In the transvaginal USG performed in the postmenopausal period, it is stated that it is important to make a differential diagnosis with endometrial cancer in case of an increase in endometrial thickness and not to undertake radical surgical interventions without an endometrial biopsy. ${ }^{[2,8,9]}$ In our case, we assume that in the premenopausal period, the helminth has recently passed from the perianal region to the vagina, and from there to the endometrial cavity, causing an endometrial irregularity and dysfunctional uterine bleeding. 
The diagnosis of Enterobius vermicularis is made by viewing the orange-red staining eggs under a microscope with the classical Sellotape swab technique. Diagnosis of extraintestinal enterobiasis cases is relatively difficult, and histopathologic evaluation is diagnosed by viewing granuloma, ova, or inflamed or degenerated adult helmint hunder a microscope. ${ }^{[1]}$ Besides, the ova can be detected in cervicovaginal smears in female genital tract infestations. ${ }^{[1,10]}$

The conventional enterobiasis treatment is based on repeat dosing of a single dose of pyrantel pamoate, albendazole, or mebendazole every two weeks. Although information about the treatment of enterobiasis cases with extraintestinal localization is limited, the agents used in the classical treatment method are preferred. ${ }^{[2,10]}$

\section{CONCLUSION}

In conclusion, the presence of an extraintestinal enterobiasis infestation, which is very rare in the female genital tract, should be kept in the mind of the clinician for preventing unnecessary and aggressive surgical interventions and protecting female reproductive health by performing a simple endometrial sampling.

\section{Disclosures}

Conflict of Interest: Written informed consent was obtained from the patient for the publication of the case report and the accompanying images.

Peer-review: Externally peer-reviewed.

Authorship contributions: Concept - H.A.I., T.G.; Design - Z.Ö.I., T.G.; Supervision - H.A.I.., Z.Ö.I.; Fundings - H.A.I., T.G.; Materials T.G.; Data collection \&/or processing - Z.Ö.I., T.G.; Analysis and/ or interpretation - H.A.I., Z.Ö.I., T.G.; Literature search - H.A.I., T.G.; Writing - H.A.I.; Critical Review - H.A.I., Z.Ö.I., T.G.

\section{REFERENCES}

1. Pigac B, Mašić $S$, Mašić V. Enterobius vermicularis in the Endometrium of the Uterus: A Case Report. Iran J Parasitol 2017;12(4):638-41.

2. Karaman Y, Bingol B, Gunenc Z, Akin O. Enterobius vermicularis infection in uterine cavity mimicking endometrial cancer: a case report. Gynecol Surg 2007;4:217-9. [CrossRef]

3. $\mathrm{Ng}$ YW, Ng SB, Low JJ. Enterobius vermicularis infestation of the endometrium - a cause of menstrual irregularity and review of literature. Ann Acad Med Singap 2011;40(11):514-5.

4. Rajesh H, Kuppusamy B, Venkataswamy C, Ganesan N. Enterobius vermicularis Infection of the Uterine Endometrium in an Infertile Female. J Obstet Gynaecol India 2020;70(1):89-91.

5. Ngui R, Ravindran S, Ong DB, Chow TK, Low KP, Nureena ZS, et al. Enterobius vermicularis salpingitis seen in the setting of ectopic pregnancy in a Malaysian patient. J Clin Microbiol 2014;52(9):3468-70. [CrossRef]

6. Rizvi G, Rawat V, Pandey HS, Kumar M. Acute abdomen: An uncommon presentation of a common intestinal nematode. Trop Parasitol 2015;5(2):123-6. [CrossRef]

7. Inal ZO, Inal HA. Comparison of Four Methods of Treating Ectopic Pregnancy: A Retrospective Cohort Study. Geburtshilfe Frauenheilkd 2018;78(1):70-7. [CrossRef]

8. al-Rufaie HK, Rix GH, Pérez Clemente MP, al-ShawafT. Pinworms and postmenopausal bleeding. J Clin Pathol 1998;51(5):4012. [CrossRef]

9. Inal ZO, Inal HA, Kucukosmanoglu I, Kucukkendirci H. Assessment of Endometrial Sampling and Histopathological Results: Analysis of 4,247 Cases. Eurasian J Med 2017;49(1):44-7. [CrossRef] 10. Smolyakov R, Talalay B, Yanai-Inbar I, Pak I, Alkan M. Enterobius vermicularis infection of female genital tract: a report of three cases and review of literature. Eur J Obstet Gynecol Reprod Biol 2003;107(2):220-2. [CrossRef] 